\title{
World Cities Formation in China: A Comparative Study of Five Pre-Eminent Cities
}

\author{
Zeyun Li \\ Geography Section, School of Humanities, Universiti Sains Malaysia \\ Penang, Malaysia, Email: lizeyun@yahoo.com \\ Sharifah Rohayah Sheikh Dawood \\ Geography Section, School of Humanities, Universiti Sains Malaysia \\ Penang, Malaysia, Email: sdawood@usm.my
}

\section{Doi:10.5901/mjss.2016.v7n6p387}

\begin{abstract}
The unprecedented economic transformation in contemporary world economy and China society embedded in the globalization circumstances has brought about robust challenging for restructuring its metropolises. The purpose of this paper is aiming to select some pioneering metropolises for examining the extent to which they can be developed as world cites in China and incorporated into the national and global scale. Since there are immense amount of big cities with distinctive functions and hierarchies within China urban territory, in this essay, we conduct the principle component analysis using SPSS for ranking the China big cities based on each city's salient competitive advantage, thereby detecting the five underlying world cities for comparative analysis. In this case, Beijing, Shanghai, Chongqing, Shenzhen and Guangzhou are identified as the pre-eminent world cities in China through some dominant parameters, which encompass the economic, political, infrastructural, urban, social and cultural specifications of the world cities. Through the specific comparative analysis of world cities in China, we can typologically find that Beijing should be considered as the political world city in terms of its tremendous political dominance, whereas Shanghai tends to be deemed as the financial and economic world city with regards to its huge quantity of multinational companies' (MNCs) regional headquarters and financial firms. As the dominant vanguards of China open door policy, Guangzhou and Shenzhen are best characterized as trading world cities. Taking together with Guangzhou and Shenzhen, Chongqing is simultaneously and actively pertaining to the second tier of world cities in China.
\end{abstract}

Keywords: World cities, China, Globalization, Comparative analysis, Principle component analysis, SPSS

\section{Introduction}

After twentieth century, since the rapid proliferation of globalization and urbanization geographically, world cities formation and interconnection is exploding in a staggering rate. The innovation of information technology and agglomeration of multinational companies (MNC) have brought about global flow of capital, labor and information. In this era of transnational circumstances, world cities interfaced with globalization trend has become one of the notable themes for research. Many scholars contribute to this fascinating area; they tend to engage in the investigation of world city network, especially interlocking nodes connection of advanced producer service firms of world cities (Beaverstock, Smith, \& Taylor, 1999; Derudder, Taylor, Witlox, \& Catalano, 2003; Taylor, Catalano, \& Walker, 2002), and global space of air passengers traffic (Derudder \& Witlox, 2005; Mahutga, Ma, Smith, \& Timberlake, 2010; Smith \& Timberlake, 2001; Li, Z., \& Dawood, S. R. S., 2016). On the other hand, some other researchers penetrate into another stream of world cities, notably in hierarchical specification and territorial attributes analysis (Brenner, 1998; Ng \& Hills, 2003; Robinson, 2011).

As globalization becomes the major trend in contemporary world economy, it plays crucial role in accelerating the world cities formation (Lo \& Yeung, 1998). Specifically, this encompasses economic, social and cultural globalization; many scholars pay more attention to the economic globalization within global studies. As globalization is closely associated to economic geography and urban studies, thus it is a dominant endogenous mechanism for global city and financial center development. Since the producer service industries develop at an unprecedented speed within the globalization circumstances, financial sector specifically dominates and becomes one of the leading producer services sector, therefore, we should find the intrinsic characteristics and driving forces of the world cities formation following these process. Globalization, widespread information technology innovation and multinational companies' expansion in this informational society enables the flow of information, capital and labors thereby enhancing the social network and transcending the spatial economy (Castells, 2011). More importantly, these kinds of space flow can accelerate the spatial 
decentralization of economic activities as well, and there is no doubt that this kind of spatial dispersal can be identified as the centripetal forces to trigger the world city formation.

After 1980s, China initiated the open door policy which enables its economy to be embedded into the global economy landscape and further foster its growth in a tremendous pace (L. J. C. Ma, 2002). It is generally believed that this kind of breakthrough is attributed to China government's open door policy and industry structure and production bases restructuring, such as tertiary industry development. However, the globalization process and diffusion as well as world cities transformation is another inevitable determinant to trigger China's economic development. Shanghai acts as the leading node of urban hierarchy, whereby it possess the most advanced infrastructure and communication system, the highest standard transportation networks and massive financial market as well as other producer services industries (F. L. Wu, 2000 ; Zeyun, L., \& Dawood, S. R. S., 2016). In short, the exploration of China world city formation, as well as the urban hierarchies' classification is still having numerous underlying aspects for further research. Therefore, the objective of this paper is to explore the following:

1) To examine the underlying mechanism for the world cities transformation in China and selecting the principle world cities derived from quantitative methods.

2) To conduct the comparative study for demonstrating the characteristics and determinants of world cities in China.

3) To classify the urban hierarchies of major world cities in China and identify each city's strategic position and function within the globalization circumstances.

\section{Study Area and Methodology}

Through the generic literature reviews of the world cities research trajectory, some research gaps will be identified. One of the obvious research gaps is attributed to the research methods, since the majority of researchers only carried out the qualitative methods in the world cities study. In terms of my research, I will conduct the combination of quantitative and qualitative analysis methods, thereby enhancing the scientific results. The study area of the research will concentrate on selected cities in China. The dramatic economic growth of China enables the country to become the second largest economic entity in the world. Undoubtedly, the world cities of China already played a dominant role in the urban hierarchies of the world cities network. Shanghai maintains the leading financial center in China; it possesses the biggest stock exchange and foreign exchange market. Besides, it also has the superior advanced producer service industries and most convenient transportation and infrastructure (urban and information) systems in Mainland china, huge amount of higher educated population and efficient employees also add an advantage for Shanghai to transform as a leading world city in the global urban system. Guangzhou and Shenzhen are the vanguards of China Open door policy from 1980s; they are the dominant locales of international trading and foreign direct investment (FDI) (Chubarov \& Brooker, 2013; Sit \& Yang, 1997).

The data collection method of the research is based on secondary data. The secondary data is derived from some financial institution websites, government official websites, books, journals, conference papers and also some other online materials, such as census data from China Statistical Yearbook, China City Statistical Yearbook, official statistics from Bank of China (Central Bank), Almanac of China's Finance and Banking and some other official documents. After collecting the sufficient data sources, some scientific methods were conducted to further analyze and find the intrinsic theories. The method is not restricted to comparative and descriptive analysis; we should explore some more interactive methods in order to enable the innovative purpose of the research. The scientific comparative studies between major global cities in China covers from Beijing, Shanghai, Shenzhen, Chongqing and Guangzhou based on our collected secondary data.

In accordance to our research objectives, the methods should explain the characteristic and determinants of world cities in China, and SPSS software analysis is applied for further findings and discussions. SPSS as the most important statistics software in social science research, it is very useful for our data analysis and hypothesis testing. This kind of statistics research using SPSS will enhance our descriptive and casual research objectives, which can identify the characteristics and indicators of world cities development in terms of descriptive research objective aspect, and testing the causality relationship between selected criterions and world cities in regard to casual research objective. Principle component analysis based on SPSS is also applied for five major world cities selection out of 36 sample cities for subsequent comparative study due to the huge quantity of metropolises in China.

With reference to the research methodology, some hypotheses are tested in the later principle component analysis section in order to identify possible linkage between selected parameters and world city development. The hypotheses are examined in following: 
Hypothesis:

1. Economic factor possesses the significantly positive relationship with world city development

2. There will be a positions correlation between infrastructure restructuring and world city development.

3. Social cultural development will affect the world city formation.

\section{Results and Discussion}

\subsection{Five principle world cities selection in China}

Table 1: Total Variance Explained

\begin{tabular}{|c|c|c|c|c|c|c|}
\hline \multirow{2}{*}{ Component } & \multicolumn{3}{|c|}{ Extraction Sums of Squared Loadings } & \multicolumn{3}{c|}{ Rotation Sums of Squared Loadings } \\
\cline { 2 - 7 } & Total & \% of Variance & Cumulative \% & Total & $\%$ of Variance & Cumulative \% \\
\hline 1 & 11.815 & 62.184 & 62.184 & 8.123 & 42.754 & 42.754 \\
2 & 2.540 & 13.368 & 75.552 & 4.112 & 21.641 & 64.395 \\
3 & 1.314 & 6.913 & 82.465 & 3.433 & 18.070 & 82.465 \\
\hline
\end{tabular}

Extraction method: Principle component analysis

Source: Compiled and analyzed by authors from China Statistical Yearbook (2014)

Table 2: Component Matrix and Rotated Component Matrix

\begin{tabular}{|c|c|c|c|c|c|c|}
\hline \multirow{2}{*}{ Parameters } & \multicolumn{3}{|c|}{ Component Matrix 1} & \multicolumn{3}{|c|}{ Rotated Component Matrix 2} \\
\hline & 1 & 2 & 3 & 1 & 2 & 3 \\
\hline Total population(10000 persons) & .720 & .630 & .109 & .156 & .743 & .593 \\
\hline Gross Regional Product (100 million RMB) & .968 & -.119 & -.096 & .835 & .343 & .380 \\
\hline Tertiary industry Gross Regional Product (100 million RMB) & .938 & -.288 & -.129 & .920 & .221 & .290 \\
\hline Passenger traffic (10000 persons) & .593 & .145 & .612 & .313 & .800 & -.098 \\
\hline Freight traffic (10000 tons) & .755 & .402 & -.114 & .347 & .486 & .623 \\
\hline Budgetary revenue of local governments(10000 RMB) & .930 & -.222 & -.116 & .871 & .259 & .318 \\
\hline Budgetary expenditure of local governments (10000 RMB) & .954 & -.068 & -.007 & .784 & .426 & .345 \\
\hline Total investment of fixed assets(10000 RMB) & .733 & .506 & -.075 & .261 & .556 & .650 \\
\hline Balance of saving deposit of residents (10000RMB) & .944 & -.224 & -.117 & .884 & .265 & .323 \\
\hline Average wage of staff and workers (RMB) & .235 & -.459 & .268 & .443 & .078 & -.368 \\
\hline Number of postal offices (unit) & .785 & .318 & .451 & .369 & .864 & .194 \\
\hline Number of subscribers of fixed telephones (10000 subscribers) & .980 & -.108 & -.060 & .834 & .381 & .368 \\
\hline Total retail sales of consumer goods (100000 RMB) & .951 & -.108 & -.213 & .826 & .257 & .462 \\
\hline Total value of import and export (10000 USD) & .770 & -.537 & .204 & .914 & .254 & -.157 \\
\hline Number of public vehicles under operation (unit) & .841 & -.325 & .255 & .831 & .431 & -.037 \\
\hline Number of theaters and music halls, cinemas (unit) & .703 & -.434 & -.214 & .837 & -.027 & .167 \\
\hline Total enrollment of regular institutions of higher education(person) & .465 & .429 & -.512 & .143 & .073 & .798 \\
\hline Hospitals and health centers(unit) & .666 & .608 & .231 & .117 & .793 & .473 \\
\hline Total volume of industrial waste water discharged (10000 tons) & .603 & .180 & -.252 & .380 & .203 & .523 \\
\hline
\end{tabular}

1. Extraction Method: Principal Component Analysis.

a. 3 components extracted.

2. Extraction Method: Principal Component Analysis.

Rotation Method: Varimax with Kaiser Normalization.

a. Rotation converged in 4 iterations.

Source: Compiled and analyzed by authors from China Statistical Yearbook (2014)

As it can be seen from above tables that total variance explained is depicted in Table 1 while component matrix and rotated component matrix are summarized in Table 2. Table 1 explicitly demonstrates the three extracted factors out of 19 parameters using normal and rotated methods of principle component analysis .And Table 2 clearly indicates the component matrix, rotated component matrix and parameters, which identified the correlations between the factors and 
the parameters.

Since there are a vast number of metropolises in China, it is not easy to identify which cities should be given the priorities to develop as the world cities. Within this study, we retrieved the data from China Statistical Yearbook in 2014 to conduct principal component analysis thereby examining the data of major 36 cities in China and detect 5 preeminent cities with the highest comprehensive score to develop as the world cities. In principle, the sample frame of 36 cities is evenly distributed in China national territory, typically covering the eastern, middle, southern and northern regions. Geographically, these four regions extraordinarily make a contribution to the huge fraction of the regional economy, culture, urban and social development compared to the western region of China, thus, western region of China is not considered in this research scope. The parameters system construction of this research is another cornerstone and inevitable array thereby guaranteeing the following principle component analysis is conducted smoothly. Since the competitive advantage is a sustainable force to enable the nations and cities to maintain the excellent performance (Porter, 2011), the urbanization, industrialization and internationalization are significantly complementing the competitive advantage of a city. The parameters system of this research ( see in left column of Table 2) are derived from the economy, infrastructure, government ,social and culture indicators of a city, specifically, these indicators are largely demonstrating the competitive advantage of a city. Therefore, we utilized the principle component analysis based on the cities' competitive advantage to elaborate the five cities selection from the sample frame.

As we can see from Table 1, the first three eigenvalues have maintained the accumulation of $82.465 \%$ of total contribution rate, which indicates the $82.465 \%$ variances of original information. Basically, the first three components can explain the majority of information while other components only can demonstrate a less quantity of information; therefore, we set these three components as the principle components.

Table 2 demonstrates the component matrixes. The component matrix is unable to clearly identify the typical initial factor loadings; therefore, a rotation method is conducted in order to eliminate the ambiguous factors of un-rotated results. It is generally believed that rotated results are much easier for further explanations and factor analysis.

The new rotated component matrix is satisfactory as clarified in Table 2. Most important, this new matrix also examines the testing hypotheses of this research. The principle component F1 has great factor loadings in tertiary industry Gross Regional Product (GRP), budgetary revenue of local governments, balancing of saving deposit of residents and total value of import and export, so we define it as the economic factor. Besides, principle component F2 is relatively high factor loadings in total population, passenger traffic and number of postal offices as well as hospitals; therefore, it is best explained as the population infrastructure factor. Lastly, the principle component F3 is associated with total enrollment of regular institutions of higher education; this component can be classified as education and social factor. Therefore, the three principle components are clearly explained on behalf of associated factors respectively.

Table 3: Cities ranking with factor score and comprehensive score

\begin{tabular}{lccccc}
\hline City & FAC1_1 & FAC2_1 & FAC3_1 & Score & Ranking \\
\hline Beijing & 3.603805 & 0.132704 & -0.15421 & 1.869558 & 1 \\
Shanghai & 3.030065 & -0.33607 & 1.360856 & 1.781051 & 2 \\
Chongqing & -1.02849 & 4.855151 & 1.518877 & 1.073683 & 3 \\
Shenzhen & 2.14266 & 1.860927 & -3.22934 & 0.891673 & 4 \\
Guangzhou & 1.137574 & -0.42591 & 1.400901 & 0.785018 & 5 \\
\hline Tianjin & 0.475744 & 0.788118 & 0.781181 & 0.624665 & 6 \\
Chengdu & -0.12236 & 1.499676 & 0.09228 & 0.350335 & 7 \\
Wuhan & 0.34474 & -0.88756 & 1.525809 & 0.280164 & 8 \\
Hangzhou & 0.339111 & -0.41696 & 0.601473 & 0.198201 & 9 \\
\hline Nanjing & 0.217241 & -0.89497 & 1.067384 & 0.111661 & 10 \\
Xi'an & -0.31463 & -0.02766 & 0.779587 & 0.000435 & 11 \\
\hline Qingdao & 0.020186 & -0.09702 & 0.039577 & -0.00632 & 12 \\
Dalian & -0.0992 & -0.21748 & 0.44006 & -0.01208 & 13 \\
\hline Ningbo & 0.174249 & -0.17909 & -0.27809 & -0.01759 & 14 \\
Shenyang & -0.12831 & -0.18606 & 0.332206 & -0.04256 & 15 \\
\hline Zhengzhou & -0.40072 & -0.12837 & 0.745979 & -0.078 & 16 \\
Harbin & -0.31705 & -0.04442 & 0.312421 & -0.10759 & 17 \\
\hline Changsha & -0.37249 & -0.08601 & 0.268334 & -0.1569 & 18 \\
Shijiazhuang & -0.61169 & -0.08621 & 0.710771 & -0.18403 & 19 \\
\hline Jinan & -0.30123 & -0.62158 & 0.468356 & -0.21667 & 20 \\
\hline Hefei & -0.60344 & 0.222536 & 0.167354 & -0.2178 & 21 \\
\hline
\end{tabular}




\begin{tabular}{lccccc}
\hline Fuzhou & -0.28812 & -0.19754 & -0.1734 & -0.23922 & 22 \\
Changchun & -0.37888 & -0.23843 & -0.09499 & -0.27983 & 23 \\
\hline Kunming & -0.55292 & 0.055687 & -0.15184 & -0.30534 & 24 \\
Xiamen & -0.13164 & -0.64074 & -0.61092 & -0.37027 & 25 \\
Nanning & -0.63879 & -0.35439 & 0.175188 & -0.38582 & 26 \\
Nanchang & -0.58721 & -0.511 & 0.099387 & -0.41678 & 27 \\
\hline Taiyuan & -0.49174 & -0.51206 & -0.26998 & -0.4485 & 28 \\
Guiyang & -0.73727 & 0.209767 & -0.60716 & -0.46026 & 29 \\
\hline Urumqi & -0.4416 & -0.31278 & -0.78758 & -0.48362 & 30 \\
Hohhot & -0.48155 & -0.54356 & -0.56136 & -0.51532 & 31 \\
\hline Lanzhou & -0.59507 & -0.62421 & -0.2328 & -0.52336 & 32 \\
Xining & -0.03924 & 0.055476 & -2.40656 & -0.53312 & 33 \\
\hline Yinchuan & -0.5526 & -0.50212 & -0.89194 & -0.61373 & 34 \\
\hline Haikou & -0.63264 & -0.28032 & -1.07186 & -0.63645 & 35 \\
Xining & -0.63651 & -0.32754 & -1.36596 & -0.71529 & 36 \\
\hline
\end{tabular}

Source: Compiled and analyzed by authors from China Statistical Yearbook (2014)

After rotation results are attained, we save the variables as regression and gain the factor scores of FAC1_1, FAC2_1 and FAC3_1. We use the factor scores and their respective contribution rates to compute the comprehensive score of each city in China, and the formula is listed as below:

Formula: Comprehensive score $=($ weight1 * fac1_1 + weight2* fac2_1 + weight $3 *$ fac3_1 $) /$ total cumulative \% (1) $=(42.757$ * fac1_1+21.641 * fac2_1 +18.070 * fac3_1 $) / 82.465$

Through SPSS calculation formula, we can easily attain the 36 cities' comprehensive scores in Table 3 . The comprehensive scores demonstrate the cities' competitive advantage status; therefore, these scores are crucial criterion for the 5 principle cities selection to develop as the world cities in China. The values of the scores are representing the deviation of the mean value, the positive values mean the cities having the higher potential to become the leading world cities while the negative values demonstrate the cities are less competitive to transform to the world cities. As we can see from the table above, Beijing and Shanghai attain the highest scores and ranking 1 and 2 positions to become the world cities in China. Lastly, we make the alternative selection based on the rankings of the comprehensive scores and detect 5 principle cities with the highest scores for world cities development, which are Beijing, Shanghai, Chongqing, Shenzhen and Guangzhou.

Table 4: Principle China world cities development in major parameters

\begin{tabular}{|c|c|c|c|c|c|}
\hline $\begin{array}{l}\text { Parameters/Cities } \\
\text { Economic and political circumstances }\end{array}$ & Beijing & Shanghai & Chongqing & Shenzhen & Guangzhou \\
\hline Multinational company (MNC) regional headquarters & $\begin{array}{c}127 \\
(2013)\end{array}$ & $\begin{array}{c}484 \\
(2014)\end{array}$ & n.a & $1(2006)$ & $16(2006)$ \\
\hline Fortune Global 500 companies headquarters,2015 & 52 & 8 & 0 & 4 & 2 \\
\hline Foreign direct investment(FDI)actually utilized (10000 USD),2013 & 852418 & 1677958 & 1059715 & 546789 & 480385 \\
\hline Foreign banks,2013 & $110+$ & $210+$ & 6 & 28 & 15 \\
\hline Total value of import and export (billion USD),2013 & 429.0 & 441.3 & 68.7 & 537.5 & 118.9 \\
\hline Total GDP (billion RMB),2013 & 1950.1 & 2160.2 & 1265.7 & 1450.0 & 1542.0 \\
\hline Tertiary industry contribution of GDP,2013 & $76.9 \%$ & $62.2 \%$ & $41.4 \%$ & $56.5 \%$ & $64.6 \%$ \\
\hline $\begin{array}{l}\text { Number of the foreign embassy and consulate(units), 2015 } \\
\text { Population and infrastructure circumstances }\end{array}$ & 165 & 75 & 10 & 0 & 53 \\
\hline Total population (10000 persons) & 1316.3 & 1432.3 & 3358.4 & 310.5 & 823.3 \\
\hline International migrants & 200000 & 176363 & 8700 & 20000 & 34000 \\
\hline Airport passenger traffic (million persons),2013 & 83.71 & 82.79 & 25.27 & 32.27 & 52.45 \\
\hline $\begin{array}{l}\text { Port Container Traffic (in thousand twenty-foot equivalent } \\
\text { units), } 2013\end{array}$ & n.a & 33617 & n.a & 23280 & 15309 \\
\hline Length of public traffic under operation(km), 2013 & 20153 & 24391 & 17142 & n.a & 17096 \\
\hline Internet users, 2013 & 1556 & 1683 & 1293 & 433 & 766 \\
\hline Social and culture circumstances & & & & & \\
\hline Number of Hospitals and Health centers, 2013 & 647 & 629 & 1502 & 119 & 253 \\
\hline Number of higher education institutions ,2013 & 89 & 68 & 63 & 10 & 80 \\
\hline
\end{tabular}




\begin{tabular}{lccccc}
\hline International students, 2014 & 74000 & 56000 & Below & Above & Above \\
Number of international tourists (10000 persons), 2013 & 387.62 & 511.07 & 76.98 & 166.82 & 278.99 \\
Number of Theaters, Music Halls and Cinemas, 2013 & 272 & 116 & 12 & n.a & 54 \\
City environment and urban layout circumstances & & & & & \\
Total urban area (sq. km), 2013 & 16410.54 & 6340.5 & $82,402.95$ & 1996.78 & 7434 \\
Volume of Industrial Waste Water Discharged (10 000 tons), 2013 & 9486 & 45400 & 33450 & 12012 & 22558 \\
Number of skyscrapers above 200 meters, 2014 & 9 & 50 & 33 & 47 & 32 \\
\hline
\end{tabular}

Source: China Statistical Yearbook (2014), China City Statistical Yearbook (2014), Almanac of China's Finance and Banking, Guangzhou Statistical Yearbook, Shenzhen Statistical Yearbook, Fortune 500 (www. fortune.com/fortune500/), Ministry of Commence of the PRC, National Bureau of Statistics of the PRC

\subsection{The comparative analysis of the selected world cities}

In this section, we will conduct the comparative analysis of selected world cities from principle component analysis using SPSS; the purpose of this part is to identify the characteristics, functions, determinants and strategic positions of these five cities in China urban hierarchies. The detailed information of comparative analysis is systematically indicated in Table 4.

As world city development is not restricted to only one or two determinants or affecting parameters, there are many factors associated to world city development. These factors are attributed to economic, social and cultural aspects. John Friedman and Saskia Sassen have summarized some significant criterions to make the world cities selection (Friedmann, 1986; Friedmann \& Wolff, 1982; Sassen, 1991). The major criterions and characteristics for world cities consist of the quantity of multinational companies (MNC) regional headquarters, a vast number of financial service industries including stocks exchange, security, insurance, banking service and real estate companies. The world cities also consist a huge population of international migrants which dominate the international division of labor articulations, a crucial trading and manufacturing center with world level port and airport, an inevitable participation in global affairs and global decisionmaking, an advanced information infrastructure and transportation systems which enables the convenient international connection, a world well-known higher education institutions and international students involvement, a deep culture environment with numerous museums and culture events and actively to attend the international sporting activities.

\subsubsection{Economics and political circumstances}

In terms of economic circumstances, Shanghai and Beijing have the highest level of economic dynamics among the five cities. Shanghai is identified as the China predominant international financial center, it possesses the highest quantity of multinational companies (MNC) regional headquarters and it is almost three times higher than the second position cityBeijing. The huge amount of MNCs' involvement in Shanghai enables its critical position within world cities network. Besides, financial industries agglomeration in Shanghai triggers it to become the dominant financial center in China. The financial institutions agglomeration, the international flow of financial information and huge amount of labor forces in financial market are indispensable aspects for Shanghai to become the world city. Apart from the powerful headquarter economy of Shanghai, Beijing is widely characterized by its crucial political implication in China, and as the capital city of China, the majority of policy-making and administrative institutions, governments and financial regulatory departments are located in Beijing, such as China Securities Regulatory Commission, China Insurance Regulatory Commission, China banking regulatory commission and the People's Bank Of China (Central bank).Thus, Beijing's special political position in China urban landscape makes it no alternative cities can replace its position. In the long term, since its proximity to central government and policy-making institutions, it should be identified as the preferential city to access to the central economic and financial information sources. Therefore, Beijing is capable to be another prospect leading world city in China. In addition to political status, Beijing's position as headquarter for competitive economy forces still cannot be ignored. In 2004, Beijing replaced Tokyo had the highest amount of Fortune Global 500 companies headquarters in the world with the quantity of 52 and even above the sum of remaining China big cities thereby enabling Beijing to accelerate to become the China premier world city.

Compared to Beijing and Shanghai, Chongqing, Guangzhou and Shenzhen are also major competitors for China world cities. Chongqing as the leading metropolitan area in middle-western part of China is experiencing the tremendous economic growth in recent years. In 2014, USD $\$ 10,597,150,000$ worth of foreign direct investment enables it to become the third position in China to attract foreign assets. Guangzhou and Shenzhen are located at Pearl River Delta region, 
which are the frontier of China open door policy; they are the most international connective cities in China. Guangzhou as the capital city of world biggest mega city region -Pearl River Delta region, it possesses the highest economic vitality, the huge territories of economic hinterland and international trade enhance its world city position. In contrast to Guangzhou, Shenzhen takes its irreplaceable advantage of its location proximity to Hong Kong; it is an innovative newly developed metropolis. The tremendous economic growth, international trade and financial market development boost its world city formation. Meanwhile Shenzhen stock exchange accompanies with Shanghai stock exchange to retain the prosperity of China stock market, and it also facilitates the regional financial market improvement.

\subsubsection{Population and infrastructure circumstances}

In terms of infrastructure development of Shanghai, it possesses two leading international airports and has a variety of international air routes to different countries and it is also one of the busiest airports in China with $706,000,000$ passenger traffic in 2014. In addition to two renowned international airports, Shanghai has one of the predominant port facilities for international trade and domestic transportation; not surprisingly, the container traffic in Shanghai is situated at top position in China as well. Due to the implication of economic globalization, an increasing number of international migrants coming to China; the major constituted countries include USA, Korea, Japan and some European countries. They play a dominant role in affecting the international division of labor and boost the China economy development, the majority of them have high educational qualification and engage in advanced producer service industry and some knowledge-based sectors such as financial and banking, accounting and some other MNC companies. These skilled international migrants are an indispensable asset for Shanghai world city formation. In addition to Shanghai, Beijing's infrastructure development also meets the high quality of international standard. According to Table 4, Beijing international airport is the busiest airport in China and ranking No.2 in the global airport rank with the vast number of international and domestic passengers and cargo traffic (The Port Authority of New York and New Jersey, 2013). The information and public traffic construction of Beijing is also in the pioneering position following Shanghai, which sustains its trading and information center status. The huge population of Beijing is beneficial for enough work forces supply in different industries, especially highly educated working labors and skilled workers. In term of migrants, Beijing not only have the vast quantity of floating population from rural areas and small cities, they also attract many international migrants and the number is the highest in China with approximately 200000 people, hence the Beijing economy development is highly dependent on this skilled migrants' contribution. As it can be seen from Table 4, Guangzhou and Shenzhen are two major ports for international trade, ranking No.2 and 3 following Shanghai, urban public transportation development also maintains the international standard with the pioneering international airport, subway system and information system(X. Ma \& Timberlake, 2008; Zacharias \& Tang, 2010). Chongqing has the highest quantity of population in China city; it is a leading metropolitan area in China as the trading, information and financial center.

\subsubsection{Social and culture circumstances}

Social and cultural aspects of world cities cover the cultural diversity and social environment, the major parameters to reflect world city status are targeted to a variety of aspects, such as the quantity of health care institutions and international recognized educational institutions, number of international students in the universities, number of global culture, sporting activities and campaigns, as well as the quantity of the international tourists every years(Knox \& Peter J. Taylor, 1995; Sassen, 1991). As we can see from the Table 4, Beijing and Shanghai still have the highest level of these indicator, Guangzhou and Shenzhen are situated at second tier while Chongqing is ranked as last one. As the residents stay in these metropolises has the variety of the cultural backgrounds, thus, the different world cities have distinctive social orders and cultural contexts. Guangzhou and Shenzhen as the frontier of China Open Door Policy in 1980s, and thus they are the native places of numerous overseas Chinese who born abroad, therefore, the social culture of these two cities is beyond the national boarder. Besides, Guangzhou and Shenzhen as the nodes of world economy, they attract a great deal of international trade. In short, Guangzhou and Shenzhen should be designated as the extroverted type of world cities. As the extroverted word city paradigms, these two cities tend be have an immense potential to attract foreign direct investment (FDI) and stimulate regional exporting and importing, hence extroverted world cities are best characterized as an articulation where transfers the primary-sector based society to a industrialization and urbanization society in the context of globalization(Li, 2004). In terms of Shanghai, it is widely acknowledged as the international financial, economic and informational center, and the local inhabitants tend to be characterized by the business and innovative talent, and they are pretty aggressive to conduct the business activities. Besides that, the number of global cultural and sporting activities hosted by Shanghai is also relatively highest in China (F. Wu, 2000). Therefore, Shanghai 
is best regarded as the aggressive world city in terms of the cultural characteristics. Beijing is an international dominant city in China; it attracted huge amount of international tourists in 2013, which demonstrates its international reputation. The endogenous social order stability of Beijing is advantageous to accumulate the highest quantity of higher educational institutions and influx of intentional students. Therefore, we can consider Beijing to be a stable world city. Last but not least, Chongqing also plays a critical role in the social order of China world cities, the simple social culture of Chongqing residents and historical catering culture contributes to its introvert type of world city. General speaking, introvert world cities have some prevailing features. They tend to acquire some central government's preferential policies to enhance the development of regional culture and economy compared to other regions, thus, these introvert cities are relative regionalism and less interact with globalization context (Goodman, 1994).

\subsubsection{City environment and urban layout circumstances}

As the world city is a dominant destination of the MNC regional headquarters and highly educated international migrants, it must provide a suitable city environment for these target groups. Shanghai and many major China metropolises already take some strategies to relocate the polluting enterprises to rural areas and less population density areas from the urban territories in order to polish up the urban air and water environment. Several industrial parks are gradually developed, which meets the international environment requirement and constructively eliminates the pollution of these mega cities.

With the exception of the environment updating strategies of major prospect China world cities, they also concentrate on urban landscape planning and construction. Shanghai has the most spectacular skyline in China urban layout, the Lujiazui financial district in Pudong new area is the leading skyscrapers and cosmopolitan financial clustering region where it possesses the highest buildings in China. Beijing is relatively distinguished from Shanghai, the protection of ancient architectural masterpieces and combination of modern skyscrapers are significantly strengthening its world cities status. In terms of the uneven development between world cities' heartlands and hinterlands, the majority of world cities in China are actively building satellite cities as control and command centers within the subnational territories thereby curtailing the uneven development among the world city-regions, and also relieving the pressure of population agglomeration and industries centralization in the heartland of world cities. Fanyu, Huadu and Guicheng are the satellite cities of Guangzhou while Baoan, Longgang and Dongguan are the major satellite cities belonging to Shenzhen. After twenty-first century, since the urbanization and industrialization paces are increasing rapidly, the gigantic urban transformation has impacted the development of several central business districts (CBD) within the world cities. Beijing CBD, Shanghai Lujiazui CBD, Guangzhou Tianhe CBD and Shenzhen Futian CBD are the four preeminent central business centers where dissemination of global information and circulation of international capital are profound. Specifically, they are also the essential composition of world cities.

\section{Conclusions}

The unprecedented economic growth in China and its embeddedness in the global economy bring about a great number of opportunities for China mega cities to evolve into the world cities within globalization tendency and circumstances. Nevertheless, in the selection of the vanguards of China world cities in this cosmopolitan circumstance, it is still a complicated and specialized procedure due to the immense quantity of China big cities and their distinctive functions and respective performances. Typologically, different cities grounded in the diversified spatial structure tend to signify the corresponding internal mechanism and external performance, this identification of the geographic features immensely contribute to its ultimate hierarchy of urban functions. Based on this research, we clearly accept all of the hypotheses. Specifically, economic factors, infrastructure factor, as well as social factor are all correlated with world city development.

Through this study, we theoretically examine 36 major metropolises in China national scale based upon the quantitative approach and eventually detect 5 predominant cities' trajectories to transform towards the world cities status. Not surprisingly, these five cities tend to have their own remarkable and salient comparative advantages to consolidate its world cities' reputation. In order to trace the typological trajectory and conceptualize the distinguished identities of these major 5 cities, we conduct the comparative analysis with respect to the different aspects in the specification of global cities, which are generated from the economy, politics, population, social-culture and urban parameters.

As we make the general comparison of principle component analysis result and comparative analysis result, we can consequently identify that these two results have the robust coincidence. Beijing, Shanghai, Chongqing, Shenzhen and Guangzhou cities are evaluated with the highest rankings and comprehensive scores in the principle component analysis. Meanwhile, they are also speculated with the same results from the comparative analysis. Overall, the results of the principle component analysis explicitly elaborate the competitive advantage of the prime metropolises in China; the 
higher rankings of cities represent the immensely competitive advantage of a city. On the other hand, the second spectrum of comparison analysis depicts that the five metropolises derived from the principle component analysis also possess the similar hierarchies of world cities taxonomy with reference to the thorough parameters comparison to develop as the world cities. Obviously, since we make the general intersections of these two results, we can conclude the consensus discourse that the cities with enormous competitive advantage also consider the robust potential to develop as the world cities simultaneously.

The above criterions of the comparative study play a crucial role in the world cities measurements. As each city has their own strength and weakness incorporated in the global cities hierarchies, they are normally characterized by distinctive functions of world cities. Beijing tends to be labeled as a political world city on the account of tremendous decision-making institutions and enlightened regulatory government departments. Shanghai is deemed as the financial and economic world city undisputedly as the result of superior aggregate economy output and diversity, as well as the agglomeration of MNC regional headquarters and financial companies. Chongqing, Guangzhou and Shenzhen pertain to the pioneers of second tier of world cities, they should be oriented to conceptualize as the manufacturing and trading world cities, this is due to the fact that they have a high quantity of labor forces supply, convenient transportation system for international trade, and pervasive industrialization and urbanization foundations as well.

Although the majority of China metropolises have sought to implement the strategies to develop as the world cities, they still have a long pathway to accomplish the extraordinary objectives compared to the benchmarking of world cities in contemporary world, such as New York, London and Hong Kong. Therefore, the local government of these mega cities should attempt to take some actions to improve their deficiencies and strengthen their comparative advantage. These ultimate strategy will guarantee the sustainable status of some world cities in China, especially Beijing and Shanghai. Furthermore, Beijing, Shanghai, Chongqing, Shenzhen and Guangzhou are premier big cities of national hierarchy in China. These cities are encountering the challenges from the national and global scales, and particularly they are intertwined by the cooperation and competition of the pervasive world cities network. Most importantly, they also ought to nurture China's economic growth and should be sensitive of the rivalry from other developing countries. Specially, they should enlarge the economic output, boost the development of the producer service industry, especially the financebased companies, induce a handful of foreign direct investment (FDI), retain the international reputation and global migrants, as well as improve the infrastructure and information technology, thereby ensuring the sustainable world cities impression. This quantitative and comparative analysis essay significantly contributes to the world cities research. However, it still has some shortcomings for addressing the world cities issues. In the future, we will engage in more comprehensive empirical study to explore the supplementary research area in terms of the world cities.

\section{Acknowledgements}

The authors would like to thank Universiti Sains Malaysia for providing financial assistance through the USM Fellowship to conduct this research smoothly.

\section{References}

Beaverstock, J. V., Smith, R. G., \& Taylor, P. J. (1999). A roster of world cities. Cities, 16(6), 445-458. doi:10.1016/s02642751(99)00042-6

Brenner, N. (1998). Global cities, glocal states: global city formation and state territorial restructuring in contemporary Europe. Review of International Political Economy, 5(1), 1-37. doi:10.1080/096922998347633

Castells, M. (2011). The rise of the network society: The information age: Economy, society, and culture (Vol. 1): John Wiley \& Sons.

Chubarov, I., \& Brooker, D. (2013). Multiple pathways to global city formation: A functional approach and review of recent evidence in China. Cities, 35, 181-189. doi:10.1016/j.cities.2013.05.008

Derudder, B., Taylor, P. J., Witlox, F., \& Catalano, G. (2003). Hierarchical tendencies and regional patterns in the world city network: A global urban analysis of 234 cities. Regional Studies, 37(9), 875-886. doi:10.1080/0034340032000143887

Derudder, B., \& Witlox, F. (2005). An appraisal of the use of airline data in assessing the world city network: A research note on data. Urban Studies, 42(13), 2371-2388. doi:10.1080/00420980500379479

Friedmann, J. (1986). The World City Hypothesis. Development and Change, 17(1), 69-83. doi:10.1111/j.1467-7660.1986.tb00231.x

Friedmann, J., \& Wolff, G. (1982). World city formation: an agenda for research and action. International Journal of Urban and Regional Research, 6(3), 309-344. doi:10.1111/j.1468-2427.1982.tb00384.x

Goodman, D. S. (1994). China deconstructs: Politics, trade and regionalism: Psychology Press.

Knox, P. L., \& Peter J. Taylor, e. (1995). World Cities in a World System Cambridge: Cambridge University Press.

Li, S. L. (2004). A Study of the Development Mode of External-oriented Urbanization. Journal of Sun Yatsen University, 44(5), 11-15.

Li, Z., \& Dawood, S. R. S. (2016). World City Network in China: A Network Analysis of Air Transportation Network. Modern Applied 
Science, 10(10), 213.

Lo, F.-c., \& Yeung, Y.-m. (1998). Globalization and the world of large cities.

Ma, L. J. C. (2002). Urban Transformation in China, 1949 - 2000: A Review and Research Agenda. Environment and Planning A, 34(9), 1545-1569. doi:10.1068/a34192

Ma, X., \& Timberlake, M. F. (2008). Identifying China's leading world city: a network approach. GeoJournal, 71(1), 19-35. doi:10.1007/s10708-008-9146-8

Mahutga, M. C., Ma, X. L., Smith, D. A., \& Timberlake, M. (2010). Economic Globalisation and the Structure of the World City System: The Case of Airline Passenger Data. Urban Studies, 47(9), 1925-1947. doi:10.1177/0042098010372684

Ng, M. K., \& Hills, P. (2003). World cities or great cities? A comparative study of five Asian metropolises. Cities, 20(3), 151-165. doi:10.1016/s0264-2751(03)00003-9

Porter, M. E. (2011). Competitive advantage of nations: creating and sustaining superior performance: Simon and Schuster.

Robinson, J. (2011). Cities in a World of Cities: The Comparative Gesture. International Journal of Urban and Regional Research, 35(1), 1-23. doi:10.1111/j.1468-2427.2010.00982.x

Sassen, S. (1991). The Global City: Princeton University Press.

Sit, V. F. S., \& Yang, C. (1997). Foreign-investment-induced Exo-urbanisation in the Pearl River Delta, China. Urban Studies, 34(4), 647677. doi:10.1080/0042098975961

Smith, D. A., \& Timberlake, M. F. (2001). World city networks and hierarchies, 1977-1997 - An empirical analysis of global air travel links. American Behavioral Scientist, 44(10), 1656-1678. doi:10.1177/00027640121958104

Taylor, P. J., Catalano, G., \& Walker, D. R. F. (2002). Measurement of the world city network. Urban Studies, 39(13), 2367-2376. doi:10.1080/00420980220080011

Wu, F. (2000). Place promotion in Shanghai, PRC. Cities, 17(5), 349-361. doi:http://dx.doi.org/10.1016/S0264-2751(00)00031-7

Wu, F. L. (2000). The global and local dimensions of place-making: Remaking Shanghai as a world city. Urban Studies, 37(8), 13591377. doi:10.1080/00420980020080161

Zacharias, J., \& Tang, Y. (2010). Restructuring and repositioning Shenzhen, China's new mega city. Progress in Planning, 73(4), 209249. doi:http://dx.doi.org/10.1016/j.progress.2010.01.002

Zeyun, L., \& Dawood, S. R. S. (2016). Development of the Regional Financial Centers in China: A Quantitative Study Based on the Province-level Data. Mediterranean Journal of Social Sciences, 7(3 S1), 374. 